\title{
Argyrophilic Nuclear Organizer Regions (AgNORs) staining to identify premalignant and malignant of the prostate lesions
}

\author{
Lidya Imelda Laksmi ${ }^{1}$, Syafruddin Illyas ${ }^{2}$, Nurjaty Chairani Siregar ${ }^{3}$, Arlinda Sari Wahyuni ${ }^{4}$ \\ ${ }^{1}$ Anatomical Pathology Department, Universitas Sumatera Utara, Medan, Indonesia \\ ${ }^{2}$ Biology Department, Universitas Sumatera Utara, Medan, Indonesia \\ ${ }^{3}$ Anatomical Pathology Department, Universitas Indonesia, Jakarta, Indonesia \\ ${ }^{4}$ Public Health Department, Universitas Sumatera Utara, Medan, Indonesia
}

Corresponding author: lidya.imelda@usu.ac.id or lidyaimelda76@gmail.com

\begin{abstract}
Introduction:There are no standard criteria defining how prominent or how frequent the nucleoli must be before they are sufficient to warrant a diagnosis of high-grade PIN. Histopathology remains as the gold standard for diagnosis of these putative precursor lesions of prostatic carcinoma. Identification of these lesions of prostate helps in early detection of carcinoma and guides the urologist to give an appropriate management to the patient.

Methods: This is diagnostic test study with cross sectional design. It was conducted at Anatomical Pathology Department in Universitas Sumatera Utara, Medan, Indonesia. There were total 55 cases taken for this study. AgNORs staining was evaluated in all cases.

Results: There is a significance difference between premalignant and malignant lesions that were stained by AgNORs ( $\mathrm{p}$ value <0,001). The AgNORs value of malignant lesions is higher than premalignant lesions.

Conclusion: Histochemical AgNORs staining can help in confound and hesitate cases to distinguish premalignant and malignant of the prostate lesions.
\end{abstract}

Keywords: Premalignant, malignant, prostate, AgNORs

\section{Introduction}

In urologist practice, premalignant lesion of the prostate does not show abnormality on clinical examination such as digital rectal examination, PSA level analysis and radiological (trans rectal ultrasound) examinations. ${ }^{1}$ Identification of these lesions from histopathology examination is a gold standard for diagnosis of these putative precursor lesions of prostatic carcinoma. We hope that this study could help in early detection of carcinoma and guide the urologist in giving appropriate management to the patient.

However, the histopathology diagnosis in benign, premalignant and malignant lesions of the prostate remains as a challenge for the pathologists. The problem of identifying basal cells on hematoxylin and eosin $(\mathrm{H} \& \mathrm{E})$ stained is occasionally it mimicks fibroblasts, basal cell hyperplasia may show prominent nucleoli with mitotic activity that may be mistaken for high-grade prostatic intraepithelial neoplasia (PIN) and in some cases, it is difficult to distinguish cribriform high-grade PIN from cribriform Gleason pattern 3 adenocarcinoma. ${ }^{2,3,4}$

Hence, this study was undertaken histochemical AgNORs staining to identify the premalignant dan malignant lesions of the prostate. It has a low cost and the procedure is simple for each examination prostate lesions. It can also help pathologists in peripheral area of development countries that have some difficulties to get the immunohistochemistry examination.

\section{Methods}

This is diagnostic test study with cross sectional design that was conducted at Anatomical Pathology Department in Universitas Sumatera Utara, Medan, Indonesia. The samples were taken from 
paraffin embedded tissue block from transurethral resection of the prostate (TUR-P) specimen and diagnosed as prostatic intraepithelial neoplasm (PIN) or adenocarcinoma prostate (malignant lesions). Total 55 cases were taken for this study. The procedure was following; the block paraffin was section into 2 to $3 \mu$, then prepared and stained with p63 immunohistochemistry to make sure that the lesion was diagnosed as PIN or malignant lesion. We used the REAL EnVision method to p63 immunohistochemistry staining with 1:100 dilution. The analysis used continuous expression from $\mathrm{p} 63$ as a benign lesion, discontinuous as a premalignant lesion (PIN) and no expression from basal cell glandular as a malignant lesion (adenocarcinoma). And then we sliced the second slides for AgNORs staining. AgNOR was observed and counted as black dots in the nuclei of at least 100 cells by using a 100x oil immersion objective. ${ }^{5}$

The aim of this study is to find the extra examination that could be used to diagnose in prostate lesions. Whereas, occasionally to make decision as a benign, premalignant and malignant lesions makes a pathologist confused and hesitate. Using histochemical AgNORs can give a low cost and simple procedure for each examination of prostate lesions. It can help pathologists to make a simple laboratory compared to immunohistochemistry examination especially peripheral pathologist in development countries.

\section{Results}

Total 55 cases were used in this study. We divided them as two lesions; (1). premalignant lesions, about 17 cases $(30,9 \%)$ and (2). malignant lesions about 38 cases $(69,1 \%)$. All of specimens were collected by transurethral resection of the prostate $(100 \%)$. Test of normality have been done and the result showed there was a significance difference between premalignant and malignant lesions about AgNORs value ( $p$ value $<0,001$ ) when the AgNORs staining of malignant lesions was higher than premalignant lesions. The range of AgNORs dots per nucleus in premalignant lesions was $\geq 12,5 \%$ with sensitivity $94,7 \%$; specificity $82,4 \%$; PPV $92,3 \%$; NPV $87,5 \%$ and accurately $90,9 \%$. The value in malignant lesions was $\geq 15 \%$ with sensitivity $92,1 \%$; specificity $88,2 \%$; PPV $94,6 \%$; NPV $83,3 \%$ and accurately $90,9 \%$.

\section{Discussion}

Prostatic intraepithelial neoplasia (PIN) was first described in the 1960s by McNeal and more precisely characterized in 1986 by $\mathrm{McNeal}$ and Bostwick at which time the entity was called intraductal neoplasia; currently, it is referred to as prostatic intraepithelial neoplasia. ${ }^{6-9} \mathrm{PIN}$ consists of architecturally benign prostatic acini or ducts lined by cytologically atypical cells. PIN is currently subcategorized into two grades, low- and high-grade PIN. The distinction between low- and high-grade PIN is the finding of prominent nucleloli in high-grade PIN. There are no standard criteria defining how prominent or how frequent the nucleoli must be before they are sufficient to warrant a diagnosis of high-grade PIN. The criteria used for diagnosing high-grade PIN is that nucleoli should be visible using a 20x lens, which has allowed us to achieve greater consistency in its diagnosis and prevent its overdiagnosis. ${ }^{3}$

Low-grade PIN consists of preexisting benign prostate glands with minimal epithelial proliferation with minimally enlarged nuclei without prominent nucleoli. If one has to hunt at 40x lens in a gland for a rare cell with prominent nucleoli, then the case should not be diagnosed as high-grade PIN. It may represent low-grade PIN, but for the reasons described in the following, the case should merely as benign prostate tissue without mentioning PIN. ${ }^{3}$

Some mimicker lesions of PIN, like: (1). central zone glands are frequently over diagnosed as high-grade PIN because their nuclei are piled up and they may be arranged in Roman bridge and cribriform glandular patterns. However, within these central zone glands, nuclei streamed parallel to the glandular bridges, in contrast to the more rigid bridges seen in high-grade PIN. Most important, central zone glands are distinguished from high-grade PIN by their lack of cytologic atypia; (2). basal cell hyperplasia may show prominent nucleoli along with mitotic activity, may be mistaken for high-grade PIN. They are different with a proliferation of small round crowded glands in basal cell hyperplasia, whereas in high-grade PIN, the atypical nuclei fill preexisting larger benign glands that are separated from 
each other by a greater amount of stroma. The nuclei in basal cell hyperplasia tend to be round and sometimes form small solid basaloid nests. In contrast, the nuclei in high-grade PIN tend to be more pseudostratified and columnar and do not occlude the glandular luminal. Within areas of basal cell hyperplasia, atypical basal cell can be seen undermining overlying benign-appearing secretory cells. The basal cells in these foci tend to have a streaming morphology parallel to the basement membrane. Highgrade PIN has full thickness cytologic atypia with the perpendicular to the basement membrane oriented nuclei. In cases of full thickness basal cell hyperplasia, where an overlying secretory cell layer may not be apparent, the luminal cytoplasm is atrophic, whereas in high-grade PIN, the luminal cells have apical cytoplasm. An additional difference between the two entities is the most cases of basal cell hyperplasia are found in transurethral resection of the prostate (TURP) specimens, indicating the growth was in the transition zone, in contrast to high-grade PIN's preferential location was in the periphery of the prostate; (3). Basal cells in benign glands, even not proliferative, can also have prominent nucleoli and be mistaken for high-grade PIN. ${ }^{10-12}$

The utilization of basal cell immunohistochemistry examination is it can help in confound and hesitate cases. Triple staining with racemase, high molecular weight cytokeratin, and p63 is emerging as a standard adjunct for the diagnosis of prostate cancer. ${ }^{13-18}$ A nuclear protein, p63 is useful for identification of basal cells, as high molecular weight cytokeratin staining. ${ }^{19}$ Shah et al. ${ }^{20}$ said that p63 was more sensitive than 34 $\beta$-E12 in benign basal cells staining, particularly in TURP (transurethral resection) specimens, offering a slight advantage over $34 \beta$-E12 in diagnostically challenging cases. Zhou et al. ${ }^{21,22}$ found that the basal cell cocktail (34ß-E12 and p63) increased the sensitivity of basal cell detection and reduced staining variability.

In this study, the diagnosis as premalignant and malignant lesions was made based on two staining, H\&E for histomorphology characters and p63 staining to identify basal cells.

This study showed that pAgNORs in premalignant lesions was lower than in malignant lesions. Many studies have shown a significantly increased proportion of proliferating cells in carcinoma compared with benign lesions, with the greatest proliferative indexes noted in high-grade carcinomas. ${ }^{23}$ Similar observations were reported in other previous studies. Rajeswari et al. found that when the volume of gland decreases with increased mucin production, with prominent nucleoli with increased proliferative activity of AgNORs and loss of tissue antigen is seen as the benign gland moves towards the premalignant and malignant prostate. The mean AgNORs count of premalignant lesions is $2.3+/-0$ which is higher than the benign lesions. ${ }^{24}$ Rita et al. found that all prostatic adenocarcinoma sample showed high AgNORs proliferating activity. ${ }^{25}$ pAgNORs study was not limited to prostate lesion study only, it has been done for other lesions, such as Ibnerase et al. that found that most malignant effusion cases have AgNORs proliferating index $>90 \% .^{26}$

Area under the curve (AUC) in this study was showed 0,962, that means the AgNORs staining is an excellent examination to distinguish premalignant and malignant lesions. In this study showed that coordinates of the curve for premalignant lesions was $\geq 12,5$ with sensitivity $94,7 \%$; specificity $82,4 \%$; PPV 92,3\%; NPV $87,5 \%$ and accurately $90,9 \%$. The value in malignant lesions was $\geq 15 \%$ with the sensitivity $92,1 \%$; specificity $88,2 \%$; PPV 94,6\%; NPV 83,3\% and accurately $90,9 \%$.

In the present study, we recommended to make AgNORs staining and $\mathrm{H} \& \mathrm{E}$ routine staining to diagnose each prostate tissue to avoid confound and hesitated diagnose.

\section{Conclusion}

Histochemical AgNORs staining can help in confound and hesitate cases to distinguish premalignant and malignant of the prostate lesions.

\section{Competing interests}

The authors declare no competing interest. 


\section{References}

1. Sakr AW, Montironi R, Epstein IJ, Rubin AM, Demarzo MA, Humphrey AP, et al. Prostatic intraepithelial neoplasia. In: Eble NJ, Sauter G, Epstein IJ, Sesterhenn AI editors. Pathologyand genetics tumors of the urinary system and male genital organs Lyon: IARC Press (World Health Organization). Classification of tumors. 2004; 6: p.193-8.

2. Epstein JI, Grignon DJ, Humphrey PA,et al. Interobserver reproducibility in the diagnosis of prostatic intraepithelial neoplasia. Am J Surg Pathol. 1995;19:873-886.

3. Epstein JI, Netto GJ. Prostatic intraepithelial neoplasia and its mimickers. Biopsy Interpretation of the Prostate. 2008;4:35-71.

4. Epstein JI, Netto GJ. Prostatic intraepithelial neoplasia and its mimickers. Biopsy Interpretation of the Prostate. 2008;4:72-104.

5. Trere D. AgNOR staining and quantification. Micron 2000;31:127-31.

6. Bostwick DG, Brawer MK. Prostatic intra-epithelial neoplasia and early invasion in prostate cancer. Cancer. 1987;59:788-794.

7. Drago JR, Mostofi FK, Lee F. Introductory remarks and workshop summary. Urol. 1989;34(suppl):23.

8. McNeal JE. Origin and development of carcinoma in the prostate. Cancer. 1969;23:24-34.

9. McNeal JE, Bostwick DG. Intraductal dysplasia: a premalignant lesion of the prostate. Hum Pathol. 1986;17:64-71.

10. Epstein JI, Netto GJ. Preneoplastic lesions in the prostate: prostatic intraepithelial neoplasia and intraductal carcinoma of the prostate. Biopsy Interpretation of the Prostate. 2015;5:38-82.

11. Srodon M, Epstein JI. Central zone histology of the prostate: a mimicker of high-grade prostatic intraepithelial neoplasia. Hum Pathol. 2002;33:518-523.

12. Devaraj LT, Bostwick DG. Atypical basal cell hyperplasia of the prostate. Immunophenotypic profile and proposed classification of basal cell proliferation. Am J Surg Pathol. 1993;17:645-659.

13. Epstein JI, Armas OA. Atypical basal cell hyperplasia of the prostate. Am J Surg Pathol. 1992;16:1205-1214.

14. Sung MT, Jiang Z, Montironi R, et al. Alpha-methylacyl-CoA racemase (P504S)/34betaE12/p63 triple cocktail stain in prostatic adenocarcinoma after hormonal therapy. Hum Pathol .2007;38:332341.

15. Molinie V, Herve JM, Lugagne PM, et al. Diagnostic utility of a p63/alpha-methyl coenzyme A racemase (p504s) cocktail in ambiguous lesions of the prostate upon needle biopsy. BJU Int. 2006;97:1109-1115.

16. Signoretti S, Waltregny D, Dilks J, et al. p63 is a prostate basal cell marker and is required for prostate development. Am J Pathol. 2000;157:1769-1775.

17. Yang XJ, McEntee M, Epstein JI. Distinction of basaloid carcinoma of the prostate from benign basal cell lesions by using immunohistochemistry for bcl-2 and Ki-67. Hum Pathol. 1998; 29:1447-1450.

18. Parsons JK, Gage WR, Nelson WG, De Marzo AM. p63 protein expression is rare in prostate adenocarcinoma: implications for cancer diagnosis and carcinogenesis. Urology. 2001;58:619-624.

19. Weinstein MH, Signoretti S, Loda M. Diagnostic utility of immunohistochemical staining for p63, a sensitive marker of prostatic basal cells. Mod Pathol. 2002;15:1302-1308.

20. Shah RB, Zhou M, LeBlanc M, et al. Comparison of the basal cell-specific markers, 34betaE12 and p63, in the diagnosis of prostate cancer. Am J Surg Pathol. 2002;26:1161-1168. 
21. Zhou M, Shah R, Shen R, Rubin MA. Basal cell cocktail (34betaE12+p63) improves the detection of prostate basal cells. Am J Surg Pathol. 2003;27:365-371.

22. Wu HH, Lapkus $\mathrm{O}$, corbin M. Comparison of 34betaE12 and p63 in 100 concecutive prostate carcinoma diagnosed by needle biopsies. Appl Immunohistochem Mol Morphol. 2004;12:285-289.

23. Khan AH, Khan SA, Chaudrhy NA, Tayyab M. Argyrophilic nucleolar organizer regions (AgNORs) pattern in different grades of transtitional cell carcinoma of urinary bladder. Ann King Edw Med Uni. 2008;14:86-89.

24. Rajeshwari K, Damale R, Dravid NV, Karibasappa GN. Argyrophilic Nucleolar Organizer Regions (AgNORs) as a Proliferative marker in various prostatic lesions. Indian journal of pathology and oncology. 2015;2(3):126-30.

25. Rita R, Delyuzar, Laksmi LI. AgNOR histochemical expression in benign prostatic hyperplasia and prostatic adenocarcinoma. IOP Conf. Series: Earth and Environmental Science 125. 2018;1-5.

26. Ibnerasa SN, Chaudhry NA and Khan SA. AgNOR proliferation index in malignant pleural and peritoneal effusion. Inter J Pathol. 2005;3(2):86-90. 